\title{
In vivo degradation and biocompatibility study of in vitro pre-degraded as-polymerized polylactide particles
}

\author{
J.E. Bergsma*, F.R. Rozema*, R.R.M. Bos* , G. Boering*, \\ W.C. de Bruijn ${ }^{\dagger}$ and A.J. Pennings ${ }^{\ddagger}$ \\ 'Department of Oral and Maxillofacial Surgery, University Hospital Groningen, P.O. B0x 30.001, 9700 RB Groningen \\ The Netherlands; 'AEM Unit, Clinical Pathological Institute I, Erasmus University of Rotterdam, $3000 \mathrm{DR}$ Rotterdam, \\ The Netherlands; 'Department of Polymer Chemistry, University of Groningen, 9700 RB Groningen, The Nether- \\ lands
}

The degradation of high molecular weight as-polymerized poly(L-lactide) (PLLA) is very slow; it takes more than $5.6 \mathrm{yr}$ for total resorption. Moreover, the degradation products of as-polymerized PLLA bone plates, consisting of numerous stable particles of high crystallinity, are related with a subcutaneous swelling in patients $3 y \mathrm{r}$ postoperatively. In order to avoid these complications, polymers were developed that are anticipated to have comparable mechanical properties but a higher degradation rate and do not degrade into highly stable particles that can induce a subcutaneous swelling. On chemical grounds it can be expected that copolymerization of PLLA with 4\% D-lactide (PLA96) or by modifying PLLA through cross-linking (CL-PLLA) will lead to less stable particles and a higher degradation rate. To evaluate the long-term suitability of these as-polymerized polymers, the biocompatibility of the degradation products should be studied. Considering the very slow degradation rate of as-polymerized PLLA, in vitro pre-degradation at elevated temperatures was used to shorten the in vivo follow-up periods. In this study, the biocompatibility and degradation of as-polymerized PLLA, PLA96 and CL-PLLA were investigated by implanting pre-degraded particulate materials subcutaneously in rats. Animals were killed after a postoperative period varying from 3 to $80 \mathrm{wk}$. Light and electron microscopical analysis and quantitative measurements were performed. The histological response of all three pre-degraded materials showed a good similarity with in vivo implanted material. Pre-degraded PLLA induced a mild foreign body reaction and showed a slow degradation rate. PLA96 and CL-PLLA had a substantially lower crystallinity, a smaller mean particle size and an enhanced degradation rate compared to PLLA. Based on the chemical and quantitative analysis, the degradation of PLA96 and CL-PLLA was much more enhanced and thus more favourable than the degradation of PLLA. Biomaterials (1995) 16 (4), 267-274

Keywords: Biodegradation, biocompatibility, in vitro pre-degradation, as-polymerized polylactides, animal model

Received 1 April 1994; accepted 26 June 1994

Poly(L-lactide) (PLLA), a biodegradable poly $\alpha$ hydroxy acid, has been lested extensively for the past decades ${ }^{1-4}$. Both in vivo and in vitro studies have shown that PLLA can be considered to be a biocompatible and biodegradable material ${ }^{5-8}$. At our department, as-polymerized high molecular weight PLLA has been successfully used for fracture fixation and orbital floor reconstructions ${ }^{8-11}$. As-polymerized PLLA has good mechanical properties compared to other biodegradable polymers but a disadvantage is that the degradation is very slow; it takes more than $5.6 \mathrm{yr}$ for total resorption ${ }^{12}$. Moreover, the degrada-

Correspondence to Dr J.E. Bergsma. tion products of these PLLA implants, numerous stable particles of high crystallinity, seem to be related with a subcutaneous swelling in patients $3 \mathrm{yr}$ postoperatively ${ }^{12-14}$.

In order to avoid these complications, polymers should be developed that have comparable mechanical properties to the original as-polymerized PLLA but a higher degradation rate and a reduced crystallinity, to avoid long-lasting presence of particles as seen with PLLA. In this study an as-polymerized copolymer of 96\% L-lactide and 4\% D-lactide (PLA96) and aspolymerized cross-linked PLLA (CL-PLLA) were used. Copolymerization of I-lactide with $4 \%$ n-lactide units will cause a much lower initial crystallinity, smaller 
and less perfect crystalline domains, which hopefully will result in an enhanced degradation rate ${ }^{15}$. Bulk copolymerization of PLLA with $1 \%$ spiro-bis-dimethylene-carbonate leads to a CL-PLLA with a much lower initial crystallinity and melting temperature, but with improved mechanical properties ${ }^{16}$.

For safe application of a newly developed biomaterial, the entire degradation and resorption should be examined befnre the implant is used. In many reports only the functioning of the implant is studied in a short-term experiment. The full process of degradation and resorption using a material in physiological settings has hardly been investigated, resulting in unexpected foreign body reactions such as sinus formation in bone or subcutaneous swellings ${ }^{12-14,17,18}$. However, the assessment of the entire in vivo degradation and resorption of as-polymerized PLLA requires a follow-ıp of at least 6 or $7 \mathrm{yr}$ due to the very slow degradation rate of as-polymerized PLLA ${ }^{14}$. The aspolymerized PLA96 and CL-PLLA copolymers are anticipated to have an increased degradation rate compared to PLLA, but to study the finaj degradation and disintegration, long-term in vivo studies again might be necessary. To avoid these long follow-up periods, in the present study in vitro pre-degradation at elevated temperatures as described by Rozema et $a .^{19}$ was used to obtain an enhanced degradation rate. Based on the fact that hydrolysis is probably the only degradation mechanism for polylactides ${ }^{20,21}$, in vitro pre-degradation at elevated temperatures is a good method to simulate physiologically degraded material.

The aim of this animal sludy was to evaluate qualitatively and quantitatively the degradation and biocompatibility of in vitro pre-degraded as-polymerized PLLA, PLA96 and CL-PLLA.

\section{MATERIALS AND METHODS}

In this study three different types of high molecular weight as-polymerized polylactides were used for predegradation, PLLA, PLA96 and CL-PLLA. The chemical properties of the non-degraded polylactides are shown in Table 1 . All polymers were synthesized according to previously published protocols ${ }^{16,22}$. Polymerization of L-lactide was performed after purification of the monomer (L- and D-lactide of CCA/Purac Biochem, the Netherlands) by recrystalization from toluene under an $\mathrm{N}_{2}$ atmosphere; the spiro-bis-dimethylene-carbonate was purified by washing with dichloromethane. The PLAs were as-polymerized under vacuum at temperatures of $110^{\circ} \mathrm{C}$ with $0.0015 \mathrm{wt} \%$ stannous-2-ethylhexanoate as a catalyst. To obtain pre-degraded material, thin chips of the polymers were hydrolytically degraded for $30 \mathrm{~h}$ in distilled water at $100^{\circ} \mathrm{C}$. Molecular

Table 1 Chemical characterization of undegraded polymers

\begin{tabular}{lccc}
\hline & PLLA & PLA96 & CL-PLLA \\
\hline$T_{m}\left({ }^{\circ} \mathrm{C}\right)$ & 187 & 156 & 161 \\
$\Delta H\left(\mathrm{~J} \mathrm{~g}^{-1}\right)$ & 60 & 26 & 49 \\
$M_{\mathrm{w}}\left(\times 10^{-3}\right)$ & 1300 & 1500 & $*$ \\
$\bar{M}_{\mathrm{w}} / \bar{M}_{\mathrm{n}}$ & 2.5 & 2.6 & -
\end{tabular}

${ }^{*}$ Cross-linked polymer ${ }^{16}$, degree of swelling in $\mathrm{CHCl}_{3}, q=10$. weight characterizations were carried out by gel permeation chromatography (GPC) at $35^{\circ} \mathrm{C}$ using a Waters ALC/ GPC 150C, calibrated with polystyrene reference materials. Differential scanning calorimetry (DSC) measurements were performed on a Perkin-Elmer DSC-7. The sample size was $5 \mathrm{mg}$ and the scan speed $10^{\circ} \mathrm{C} \mathrm{min}^{-1}$.

\section{Animal study}

To simulate the densely packed PLLA particles as seen in patients, $80 \mathrm{mg}$ of each pre-degraded polymer was placed in No. 3 gelatine capsules. The filled capsules were sterilized with $1.8 \mathrm{Mrad}$ gamma irradiation. A total of 20 male Wistar Albino rats, weighing $300 \mathrm{~g}$, were used. The rats were anaesthetized with a nitrous oxide-oxygen-fluothane mixture. The dorsal hair was clipped and the skin was prepped with iodine. Subsequently, six incisions were made on the back of the rat and in bluntly created subcutaneous pockets, two capsules of each polymer were inserted. After implantation the skin was closed with Dexon ${ }^{(\mathbb{B}}$ resorhable sutures. After postoperative periods of $3,5,8,12$, $16,32,50,60,70$ and $80 \mathrm{wk}$, two rats were killed. The tissues at the implantation sites and the area containing the brachial and axillary lymph nodes were generously excised and fixed in $2 \%(\mathrm{v} / \mathrm{v})$ glutaraldehyde in $0.1 \mathrm{M}$ phosphate buffer ( $\mathrm{pH} 7.4$ ) for $1 \mathrm{wk}$ at $4^{\circ} \mathrm{C}$. Twomillimetre-thick slices were cut perpendicular to the long axis of the excised tissue. Subsequently, the sections were dehydrated in graded series of ethanol. The sections were embedded in glycol methacrylate (GMA), polymerized for $24 \mathrm{~h}$ at $-20^{\circ} \mathrm{C}$. Sections of $2 \mu \mathrm{m}$ were made (Jung microtome 1140/autocut), which were stained with toluidine blue and basic fuchsin. For transmission electron microscopy (TEM), half of the sections with the longest implantation period, $80 \mathrm{wk}$, were fixed in $2 \%(\mathrm{v} / \mathrm{v})$ glutaraldehyde in $0.1 \mathrm{M}$ phosphate buffer ( $\mathrm{pH} \mathrm{7.4)}$ for at least 1 wk at $4^{\circ} \mathrm{C}$. Postfixation was performed with $1 \mathrm{wt} \% \mathrm{OsO}_{4}$, to which $\mathrm{K}_{4} \mathrm{Fe}(\mathrm{CN})_{6} \cdot 3 \mathrm{H}_{2} \mathrm{O}$ was added to a final concentration of $0.05 \mathrm{M}$. The material was dehydrated in series of 70,80 , 90 and $100 \%$ acetone. The sections were embedded in LX 112 epoxy resin and polymerized for $24 \mathrm{~h}$ at $60^{\circ} \mathrm{C}$. The ultrathin sections were stained with uranyl acetate-lead citrate. For TEM, a Zeiss EM 902 was used, operated at $80 \mathrm{kV}$.

\section{Quantification of the pre-degraded material}

Light microscopic sections of each polymer $(N=4)$ were used to determine the mean number of extracellular particles per frame area, the mean particle size and the polymer area fraction per frame area with a Quantimed 520 image analysis system (Cambridge Instruments, Cambridge, UK). All sections were analysed at $\times 100$ magnification. To determine the statistical significance of a decrease in the mean particle size or polymer area fraction, the regression with implantation time was calculated.

\section{RESULTS}

The chemical characteristics of the pre-degraded materials prior to implantation are presented in Table 
Table 2 Hydrolytic degradation for $30 \mathrm{~h}$ in distilled water at $100^{\circ} \mathrm{C}$

\begin{tabular}{lccc}
\hline & PLLA & PLA96 & CL-PLLA \\
\hline Loss of mass (\%) & 9.5 & 26.2 & 14.2 \\
$T_{\mathrm{m}}\left({ }^{\circ} \mathrm{C}\right)$ & 180 & 152 & 163.5 \\
$\Delta H\left(\mathrm{~J} \mathrm{~g}^{-1}\right)$ & 82.9 & 60.5 & 55.6 \\
$\bar{M}_{\mathrm{w}} \bar{M}_{\mathrm{w}} / \bar{M}_{\mathrm{n}}$ & 16600 & 2000 & - \\
\hline
\end{tabular}

2. The loss of mass after pre-degradation of the PLA96 was substantially higher than those of PLLA and CLPLLA. During pre-degradation there was an increase in the heat of fusion for all three materials, from 62 to $83 \mathrm{Jg}^{-1}$ for PLLA, 26 to $60 \mathrm{Jg}^{-1}$ for PLA96 and 48 to $55 \mathrm{Jg}^{-1}$ for CL-PLLA. The weight average molecular weight of the pre-degraded PLLA dropped to 16000 , the $\bar{M}_{\mathrm{w}}$ of the pre-degraded PLA96 decreased sharply to 2000. The degree of polydispersity was 4.4 and 6.1 for PLA 96 and PLLA, respectively.

The mean particle size and the area fraction of the three polymers with implantation time are presented in Table 3. The mean particle size of the pre-degraded PLLA at week 3 was a factor of 12 higher compared to the pre-degraded PLA96 particles and a factor of 4.5 higher compared to the pre-degraded CL-PLLA. Between 3 and $80 \mathrm{wk}$, in PLLA implants the mean particle size and the area fraction showed a significant regression $(P<0.01$ and $P<0.05$, respcctively) with implantation time. The mean PLA96 particle size decreased with implantation time, but at $32 \mathrm{wk}$ there was an increase, while the total number of particles decreased. The area fraction of the PLA96 particles showed a gradual and significant $(P<0.05)$ decrease, from $22.7 \%$ at $3 \mathrm{wk}$ to $5.2 \%$ at $32 \mathrm{wk}$, which was the last measuring point. In the period from 3 to $80 \mathrm{wk}$, there was a significant $(P<0.05)$ decrease in the mean particle size of CL-PLLA particles. In the same period, the area fraction of the CL-PLLA particles decreased significantly $(P<0.05)$ from 27.4 to $6.4 \%$.

\section{Histological analysis}

For all implants, at 21 days an acute inflammatory reaction due to the operation was no longer observed. Neutrophils, plasma cells or lymphocytes were rarely seen in any of the explants. At $3 \mathrm{wk}$, the PLLA particles were surrounded and individually embedded by young fibrous tissue with long slender fibrocytes, macrophages and foreign body giant cells (Figure 1). From 16 wk on, a mature and relatively hypocellular fibrous capsule was observed. Invagination of cells or collagen into the PLLA particles was rarely observed up to $50 \mathrm{wk}$ of implantation (Figure 2). After $70 \mathrm{wk}$ of implantation, fragmentation and the formation of smaller particles, which were internalized by phagocytizing cells, could be observed. The PLLA implanted rats showed only a small number of macrophages with internalized fragments, compared to the other materials, after $80 \mathrm{wk}$ of implantation. Using TEM, the phagocytic macrophages had a normal appearance and were embedded in mature collagen (Figure 3). Nonelectron-dense PLLA particles were present freely in the cytoplasm of the macrophages or in membranebound vacuoles. These PLLA particles had an irregular shape and some particles showed a lamellar or needlelike structure.

After 3 wk of implantation, the PLA96 particles were embedded in young fibrous tissue which was infiltrated by cells, mainly macrophages, fibrocytes, foreign body giant cells and some lymphocytes (Figure 4). After $16 \mathrm{wk}$, the number of giant cells and fibrocytes had diminished but the number of macrophages, many with a large and foamy appearance, seemed to have increased. Under crossed Nicol prisms birefringent PLA96 particles were observed intracellularly in these foamy macrophages. The surface of the remaining extracellular particles showed cracks and invasion by the cytoplasm of adjacent macrophages (Figure 5). From week 50, extracellularly positioned particles were no longer observed and the number of foamy macrophages had increased even further. At week 80, intra- or extracellular particles could no longer be observed using a light microscope. TEM images of the $80 \mathrm{wk}$ PLA96implanted rats showed numerous macrophages with abundant amounts of lamellar PLA96 material (Figure 6). The particles were packed in membrane-bound vacuoles that could be described as phagosomes. These highly packed macrophages did not show any signs of cell damage such as swollen mitochondria or rough endoplasmic reticulum.

The CL-PLLA particles showed a similar encapsulation by fibrous tissue compared with the PLLA particles after $3 \mathrm{wk}$ of implantation (Figure 7). After $16 \mathrm{wk}$, the CL-PLLA particles showed fragmentation

Table 3 The mean particle size, polymer fraction and number of particles per frame area as a function of implantation time

\begin{tabular}{|c|c|c|c|c|c|c|}
\hline $\begin{array}{l}\text { Weeks of } \\
\text { implantation }\end{array}$ & $\begin{array}{l}\text { Mean particle } \\
\text { size }\left(\mathrm{mm}^{2}\right) \\
\text { PLLA } / N^{*}\end{array}$ & $\begin{array}{l}\text { PLLA area } \\
\text { fraction } \\
(\%)\end{array}$ & $\begin{array}{l}\text { Mean particle } \\
\text { size }\left(\mathrm{mm}^{2}\right) \\
\text { PLA96/N }\end{array}$ & $\begin{array}{l}\text { PLA area } \\
\text { fraction } \\
(\%)\end{array}$ & $\begin{array}{l}\text { Mean particle } \\
\text { size }\left(\mathrm{mm}^{2}\right) \\
\text { CL-PLLA/N }\end{array}$ & $\begin{array}{l}\text { CL-PLLA } \\
\text { area fraction } \\
(\%)\end{array}$ \\
\hline $\begin{array}{r}3 \\
5 \\
8 \\
16 \\
32 \\
50 \\
80\end{array}$ & $\begin{array}{l}4.611 \pm 8.440^{\dagger} / 250 \\
4.501 \pm 8.904 / 274 \\
4.378 \pm 7.943 / 280 \\
3.652 \pm 10.729 / 292 \\
3.635 \pm 6.544 .219 \\
2.734 \pm 5.815 / 323 \\
2.742 \pm 5.719 / 267\end{array}$ & $\begin{array}{l}47.1 \pm 2.2^{\ddagger} \\
48.6 \pm 1.8 \\
48.7 \pm 2.4 \\
49.1 \pm 2.2 \\
37.8 \pm 9.1 \\
38.7 \pm 6.3 \\
32.8 \pm 6\end{array}$ & $\begin{array}{l}0.369 \pm 0.604 / 1208 \\
0.351 \pm 0.905 / 1066 \\
0.313 \pm 0.438 / 1193 \\
0.280 \pm 0.364 / 1054 \\
0.615 \pm 0.250 / 76 \\
\text { no longer detectable }\end{array}$ & $\begin{array}{c}22.7 \pm 4.3^{\ddagger} \\
21.7 \pm 3.9 \\
16.9 \pm 5.1 \\
16.2 \pm 2 \\
5.2 \pm 2.3\end{array}$ & $\begin{array}{l}1.027 \pm 1.429^{\S} / 720 \\
0.935 \pm 1.192 / 680 \\
0.905 \pm 1.165 / 676 \\
0.887 \pm 1.228 / 703 \\
0.782 \pm 0.9499 / 586 \\
0.633 \pm 0.828 / 570 \\
0.837 \pm 0.594 / 109\end{array}$ & $\begin{array}{l}34.3 \pm 1.6^{\ddagger} \\
33.2 \pm 2 \\
33.8 \pm 2.3 \\
32.8 \pm 2.1 \\
28.1 \pm 2 \\
27.4 \pm 3 \\
6.4 \pm 3.4\end{array}$ \\
\hline
\end{tabular}

${ }^{*} N$ is the number of measured particles per frame area

${ }^{t}$ Significant regression $(P<0.01)$ of the mean PLLA particie size with implantation time

tSignificant regression $(P<0.05)$ of the surface area with implantation time

Significant regression $(P<0.05)$ of the mean CL-PLLA particle size with implantation time. 


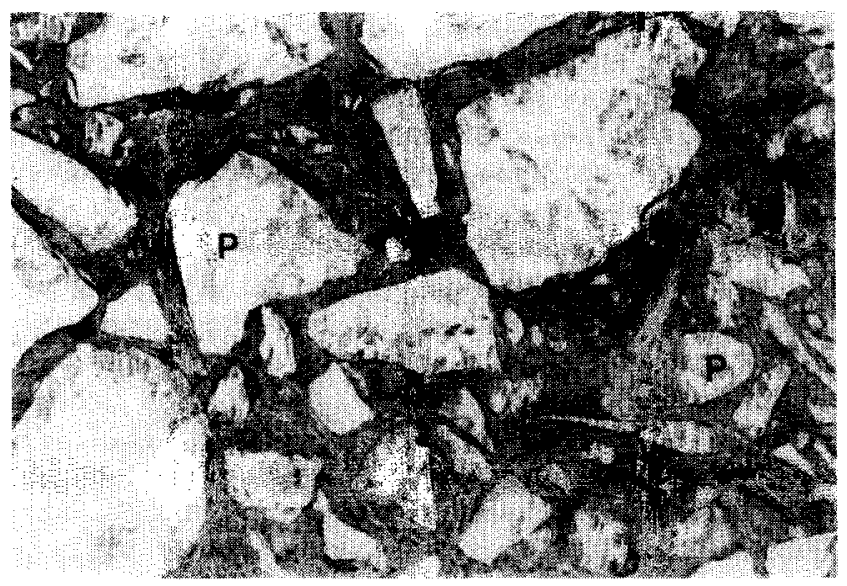

Figure 1 Light microscopic micrograph of PLLA particles (P) and connective tissue (C) after $3 \mathrm{wk}$ of implantation. Toluidine blue, original magnification $\times 150$.

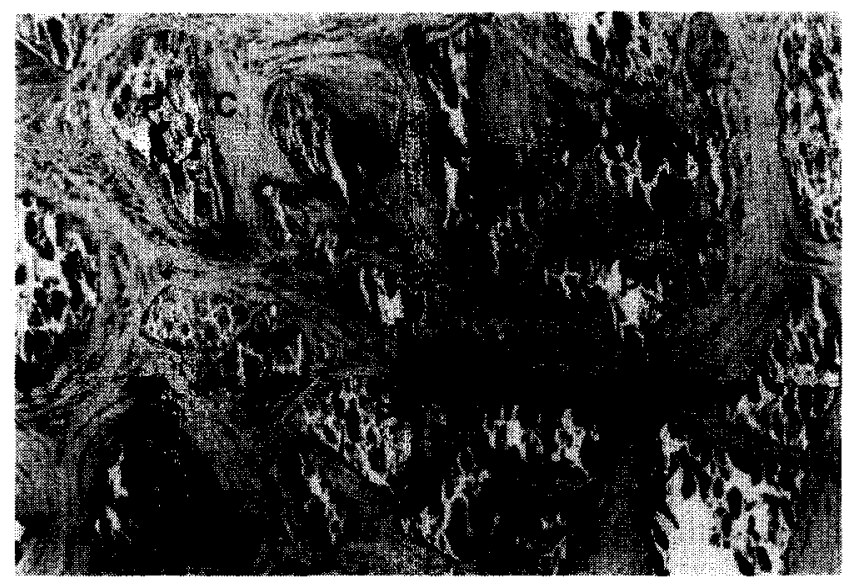

Figure 2 PLLA particles (P) encapsulated by mature fibrous connective tissue after $50 \mathrm{wk}$ of implantation. Toluidine blue, original magnification $\times 150$

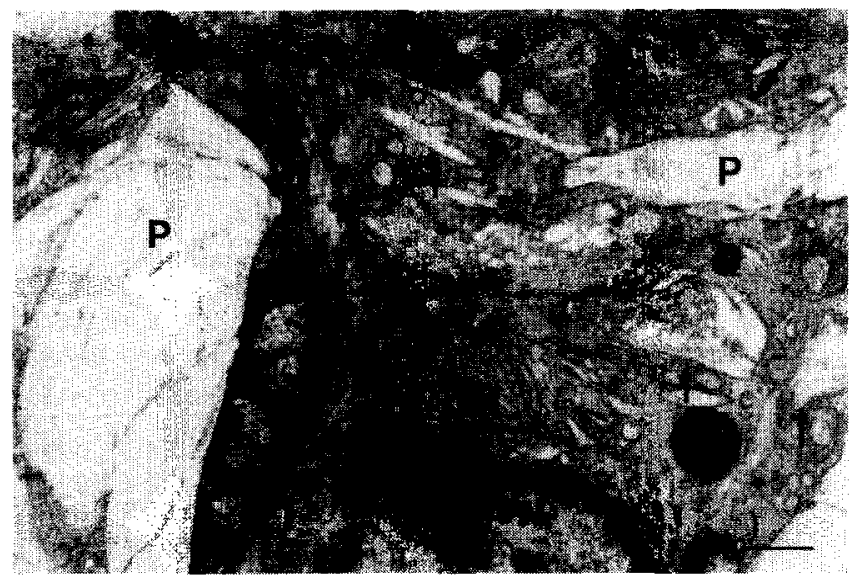

Figure 3 Transmission electron microscopic (TEM) photograph, taken after 80 wk of implantation, of intracellular PLLA particles (P) in membrane-bound vacuoles (arrows). The endoplasmic reticulum (ER) has a normal appearance. At the bottom the nucleus $(N)$ of the cell is visible. Bar $=1 \mu \mathrm{m}$

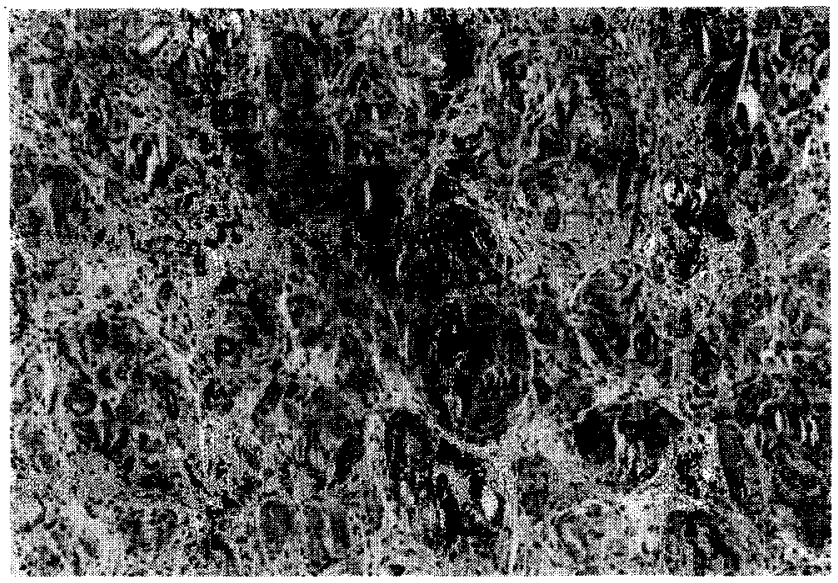

Figure 4 Light microscopic micrograph, taken after $3 w k$ of implantation, of PLA96 particles $(P)$ which are embedded in young fibrous tissue and cells. Toluidine blue, original magnification $\times 150$

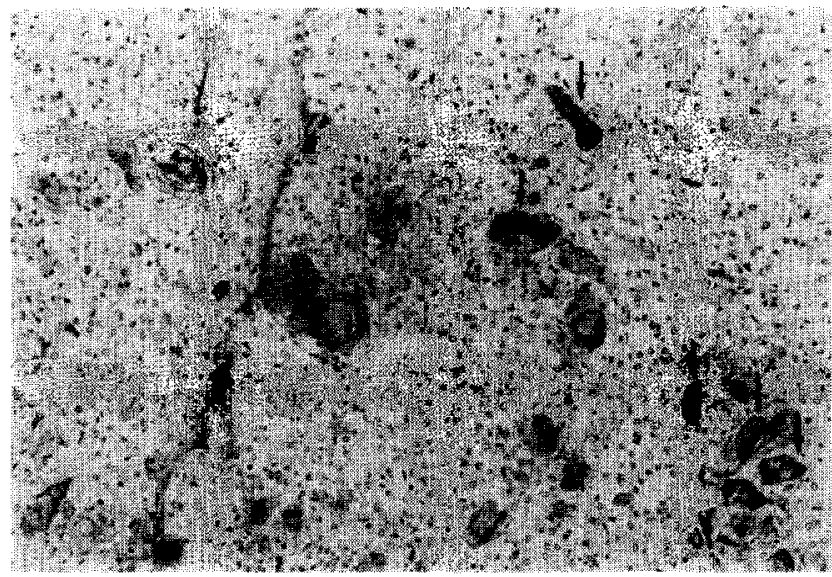

Figure 5 After 30 wk of implantation, large fields with foamy macrophages are observed. Only a limited number of extracellular PLA96 particles (arrows) can be observed. Toluidine blue, original magnification $\times 150$.

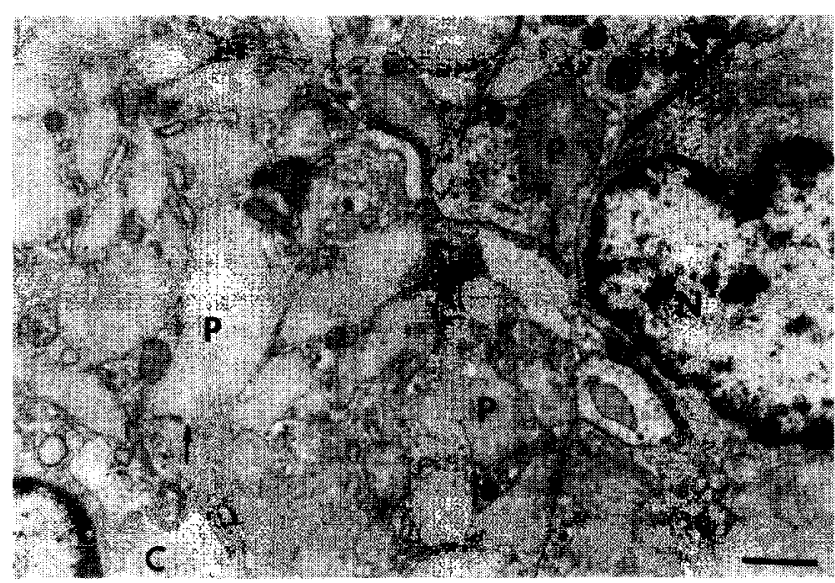

Figure 6 Transmission electron microscopic photograph of a highly packed macrophage with membrane-bound conglomerates (arrows) of PLA96 (P) particles. The cells are embedded by sheets of collagen (C). N, nucleus. $\operatorname{Bar}=1 \mu \mathrm{m}$ 


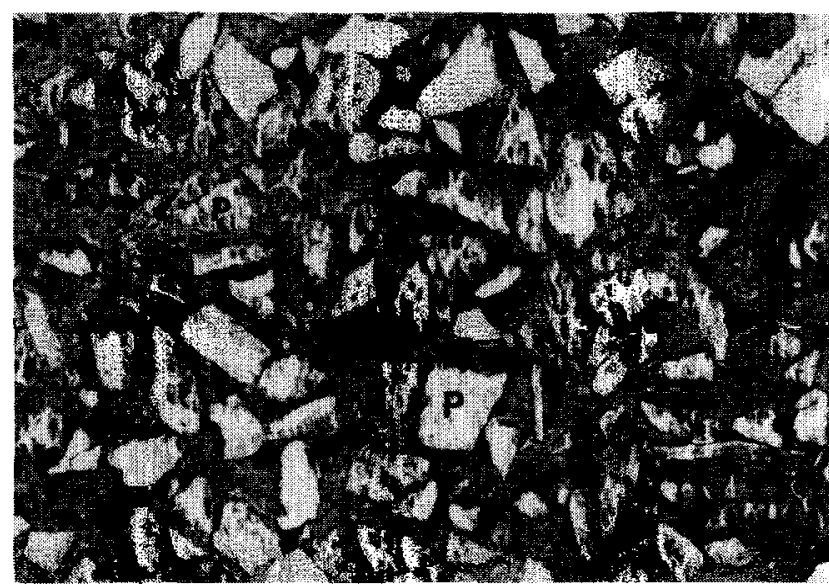

Figure 7 Light microscopic micrograph of CL-PLLA particles (P) with young fibrous tissue and cells like macrophages, fibrocytes and foreign body giant cells (arrows) after $3 \mathrm{wk}$ of implantation. Toluidine blue, original magnification $\times 150$.

and ingrowth by cells and collagen. With longer implantation periods the total number and the mean particle size showed a gradual decrease. From $50 \mathrm{wk}$, fields of large particles were interlaced with collagen, macrophages and foreign body giant cells (Figure 8). Some of these macrophages had a foamy appearance and showed birefringent material under crnssed Nicol prisms. After $80 \mathrm{wk}$ of implantation, only a limited number of extracellularly positioned birefringent particles could be observed. Intracellularly in foamy macrophages, birefringent particles were clearly visible under crossed Nicol prisms. TEM analysis of the $\mathrm{CL}$ PLLA after $80 \mathrm{wk}$ of implantation showed numerous macrophages that were fully packed with phagosomes that contained particles with needle-like or lamellar structures (Figure 9). These macrophages and extracellularly positioned particles were surrounded by dense connective tissue. There were no clear signs of cell damage, although some mitochondria appeared to be swollen.

Light microscopy under crossed Nicol prisms of

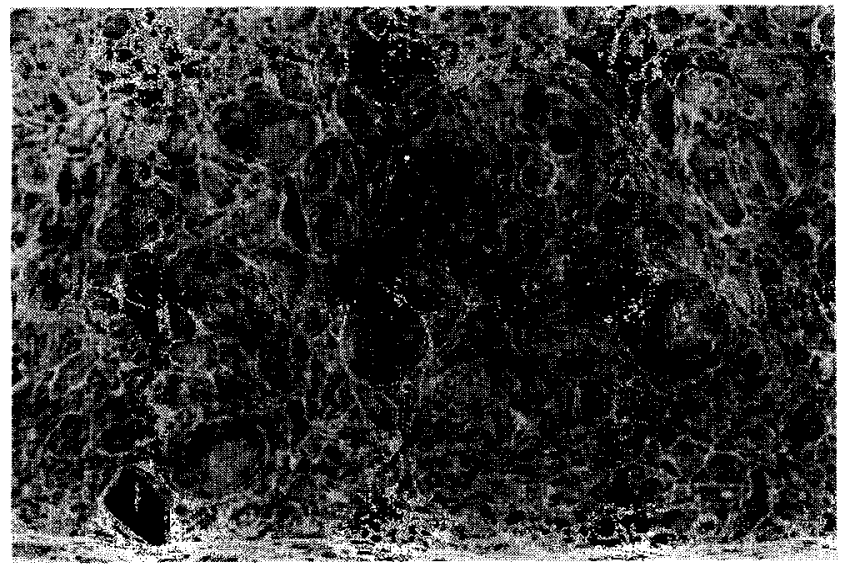

Figure 8 After $\mathbf{5 0} \mathrm{wk}$, the mean particle size and polymer fraction of CL-PLLA has decreased. Both intracellular (in macrophages) and extracellular CL-PLLA particles were observed $(P)$. Toluidine blue, original magnification $\times 150$.

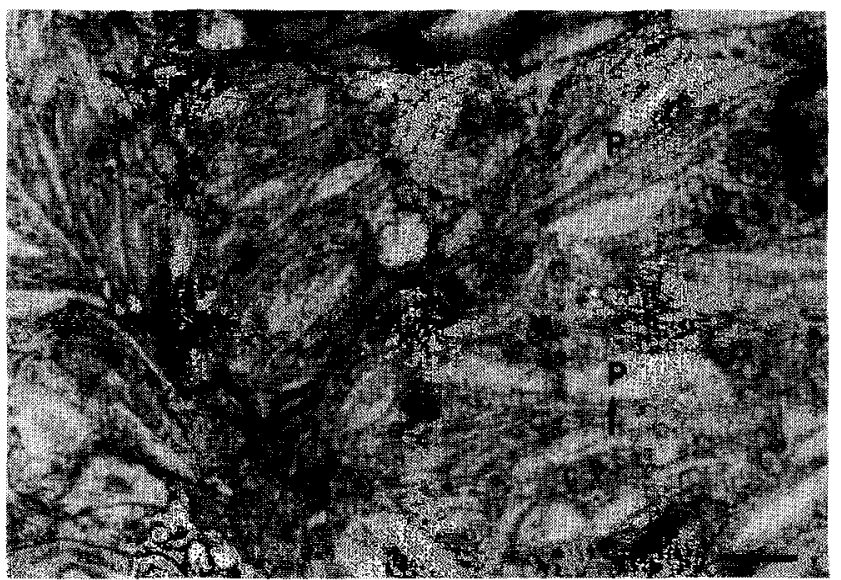

Figure 9 Transmission electron microscopic photograph of fields of needle-like CL-PLLA particles $(P)$, which are mostly located in membrane-bound vacuoles that can be described as phagosomes (arrows). Bar $=1 \mu \mathrm{m}$

excised lymph nodes did not show any sign of the presence of polymer particles in any of the rats.

\section{DISCUSSION}

In this study, the final degradation and biocompatibility of the degradation products of as-polymerized PLLA and two newly developed polymers were evaluated using in vitro pre-degraded particles. Chemical characterization of the pre-degraded PLLA showed an increase in the heat of fusion from 65 to $85 \mathrm{Jg}^{-1}$, which is indicative of an increase in crystallinity. This increase in the heat of fusion, which is due to recrystallization, clearly resembled the physiological degradation as seen with patient material ${ }^{23}$. After predegradation, PLA96 and CL-PLLA particles also showed recrystallization and a slight decrease in melting temperature, but the heat of fusion, indicative of crystallinity, remained substantially lower when compared to PLLA. The incorporation of $4 \%$ D-lactide or cross-linking with $1 \%$ spiro-bis-DMC seems to be enough to cause smaller and less perfect crystalline domains and an increased rate of hydrolysis when compared to PLLA. Due to these factors, PLA96 and CL-PLLA had a higher degradation rate, a substantially higher loss of mass and the mean particle size was smaller when compared to PLLA. This conclusion is in agreement with results of a study of Zhang et al. ${ }^{24}$, where they describe that the molecular weight, strength and mass loss by PLA96 samples was much faster than by the homopolymer PLIA. The initial degree of polydispersity of PLA96 and PLLA was 2.5 and 2.6, respectively, which are normal values for a polyester prepared by ring opening. Both PLA96 and PLLA showed a steep decrease in average molecular weight, as might be expected, and due to the atrandom chain scission caused by the hydrolytic degradation, the degree of polydispersity is also expected to increase.

All three polymers used in this study were high molecular weight as-polymerized and semi-crystalline. Factors like processing, molecular weight, residual 
monomer and crystallinity all have a great influence on the degradation rate, mechanical and biological characteristics of a polymer ${ }^{25}$. According to Chawla and Chang $^{26}$, PLLA samples with a low molecular weight degraded significantly faster than PLLA samples with relatively high molecular weights. The importance of the amount of residual monomer in a polymer was studied by Nakamura et $a l^{27}$; they concluded that polymers containing relatively high levels of monomer showed a much more enhanced degradation rate with significant differences in the decrease in molecular weight and material weight. Zhang et al. ${ }^{24}$ described that the as-polymerized PLLA and PLA96 used in their study had a low purity which caused a very rapid initial degradation rate, while melt processed polymers with a high degree of purity went through a lag phase and then showed a rapid degradation. They concluded that the degree of purity if the most critical factor affecting hydrolytic degradation. The as-polymerized polymers as used in the present study had a residual monomer concentration of about $1 \%$ and contained some residual catalyst. Indeed, the molecular weight and the mechanical properties of as-polymerized PLLA in aqueous solution showed a rapid initial decrease ${ }^{8}$. However, after this initial phase of degradation, the crystallinity becomes an important factor influencing the degradation rate. In a study with injection moulded PLLA and as-polymerized PLLA, Pistner et $a l^{28}$ observed that the amorphous injection moulded PLLA had a more enhanced degradation and disintegration rate compared to the crystalline as-polymerized PLLA implants. After $90 \mathrm{wk}$ of implantation, the amorphous PLLA had disintegrated into fragments while the as-polymerized crystalline PLLA still had its original shape. The injection moulded PLLA in the study of Pistner et al. evoked, after $1 \mathrm{yr}$ of implantation, an increased cellular reaction, consisting mainly of foamy macrophages and foreign body cells. In another study of Pistner ${ }^{29}$, the as-polymerized crystalline PLLA evoked a similar histological reaction with foamy macrophages, but only after 106 wk of implantation. It is therefore probable that the final degradation phase of a degradable polymer is accompanied by a similar histological reaction, characterized by an increase of cellular activity ${ }^{30}$, although the onset and the intensity of this reaction depends on the polymers used.

The degradation and disintegration of the implants and histological changes they induce was monitored by a quantification of the mean particle size, the number of particles per area, and the polymer and tissue area fraction. For all particles types the standard deviation was high due to the high variation in the minimum and maximum size, which was probably caused by the at-random disintegration of the particles and by the fact that the histological sections run through the irregular shaped particles. PLA96 had the highest degradation and disintegration rates; the number of detectable extracellularly positioned particles per frame area decreased from 1208 at $3 \mathrm{wk}$ to 76 at $32 \mathrm{wk}$. In this period, large numbers of small particles were internalized and could no longer be counted. The polymer fraction area of the remaining particles was still $5.2 \%$ at $32 \mathrm{wk}$, indicating that the remaining extracellular particles were relatively large, which may account for the increase in mean particle size between 16 and $32 \mathrm{wk}$. After $80 \mathrm{wk}$, a comparable decrease in the number of measured CL-PLLA particles and an increase in the mean particle size was observed.

In the period between 32 and $80 \mathrm{wk}$, the PLA96 particles and to a lesser extent the CL-PLLA particles had disintegrated into small particles that were internalized by large fields of foamy macrophages, thus evoking a final cellular response. The fields of macrophages with internalized particles greatly resembled the situation of the patients with physiologically degraded PLLA after $5.6 \mathrm{yr}^{14}$. These histological data suggest that there is little variation in the qualitative characteristics of the tissue reaction; the cell types appear to be the same for the three in vitro predegraded implants and for physiologically degraded PLLA. The absence of qualitative histological differences among the three pre-degraded polymers corresponds with a study of Behling and Spector ${ }^{31}$ with two chemically different polymers, polyethylene and polysulphone. Their study suggests that the factors which govern the type of cells seen at the implant site are the same, regardless of differences in chemistry or structure. This inplies that when nontoxic particles are implanted, the chemical composition, the degradation rate, the size or surface area of the implanted particles do not have a significant influence on the kind of cells that are attracted.

However, quantitative measurements of the histological response indicates substantial differences among the three implant materials. After 3 wk of implantation, the PLA96 particles area fraction was $22 \%$ of the measured frame area, which implies that $78 \%$ of the surface area was occupied by cells and enveloping fibrous tissue. For CL-PLLA it was $34 \%$ particles and $66 \%$ cells and fibrous tissue per frame area, and for the PLLA particles it was respectively $50 \%$ particles and $50 \%$ cells and fibrous tissue. This suggests that the smaller PLA96 particles evoke a more intense histological response compared to PLLA. Maguire et $a^{32}$ suggest in an in vivo study with polyethylene and methylmethacrylate particles that the degree of biological reaction depends mainly on the size and surface of the particles. Sevatsjanova et al. ${ }^{33}$ described that the connective tissue reaction to an implant is influenced by a number of factors, one being its size. The PLA96 particles were a factor of 11 smaller and the CL-PLLA particles a factor of 4.5 compared to the PLLA particles, which seems to correlate with the intensity of the tissue reaction. The results of this study do not show which factor is the most dominant, but the mean particle size may have a great influence on the intensity of the tissue reaction. The pre-degradation in this study was similar for all implants, which implies that the mean particle size depended merely on the chemical composition. For a comparative quantitative and qualitative biocompatibility testing of chemically different materials, the mean particle size should be the same, since the tissue reaction is directly dependent on the size of the implant.

In a study on osteolytic changes accompanying the degradation of polyglycolide pins, Röstman ${ }^{34}$ described that specimens obtained from patients with 
a clinically detectable reaction showed an identical histopathological reaction as the patients without any clinical signs. The present study showed that the degradation and disintegration mechanisms and the qualitative histological reaction of the in vitro predegraded polymers and the physiologically degraded PLLA material are probably identical. This implies that this study does not exclude the possibility that when PLA96 or CL-PLLA implants are used in a clinical setting, for example as bone plates, they might induce a detectable foreign body reaction. as seen with PLLA plates used in patients. However, the moment of clinical manifestation, the intensity and duration of such a possible foreign body reaction are factors that are directly dependent on the chemical structure of the implant, since the rate of degradation and the intensity of the histological reaction vary among the three implants. Further studies are necessary to determine whether these newly developed polymers will induce clinically detectable foreign body reactions when used in physiological settings and, if so, what the most important factors influencing the intensity of this reaction are.

\section{REFERENCES}

1 Leenslag JW, Pennings AJ, Bos RRM, Rozema FR, Boering G. Resorbable materials of poly(L-lactide). VI. Plates and screws for internal fracture fixation. Biomaterials 1987; 8: 70-73.

2 Gogolewski S, Pennings AJ. Resorbable materials of poly(L-lactide) 2. Fibers spun from solutions of poly(Llactide) in good solvents. I Appl Polym Sci 1983; 28; 1045-1061.

3 Gogolewski S, Pennings AJ. Resorbable materials of poly(L-lactide). 3. Porous materials for medical application. Colloid Sci 1983; 261: 477-484.

4 Leenslag JW, Gogolewski S, Pennings AJ. Resorbable materials of poly(L-lactide). 5. Influence of secondary structure on the mechanical properties and hydrolyzability of poly(L-lactide) fibers produced by a dryspinning method. I Appl Polym Sci 1984; 29: 28292842.

5 Kulkarni RK, Moore EG, Hegely AF, Leonard F. Biodegradable poly(lactic acid) polymers. $J$ Biomed Mater Res 1971; 5: 169-181.

6 Vert M, Christel P, Chabot F, Leray J. Bioresorbable plastic materials for bone surgery. In: Hastings GW, Ducheyne P, eds. Macromolecular Biomaterials. Boca Raton, FL: CRC Press, 1984: 120-142.

7 Cutright DE, Perez B, Beasly JD, Larson WJ, Posey WR. Degradation rates of polymers and copolymers of polylactic and polyglycolic acids. Oral Surg 1974; 37: 142-152.

8 Bos RRM, Rozema FR, Boering G, et al. Degradation of and tissue reaction to biodegradable poly(L-lactide) for use as internal fixation of fractures. A study in rats. Biomalerials 1991; 12: 32-36.

9 Bos RRM, Rozema FR, Boering G, Nijenhuis AJ, Pennings AJ, Jansen HWB. Bone plates and screws of bioabsorbable poly(L-lactide). An animal pilot study.. Br J Oral Maxillofac Surg 1989; 27: 467-476.

10 Bos RRM, Ruzema FR, Buering G, Nijenhuis AJ, Pennings AJ, Verwey AB. Resorbable poly(L-lactide) plates and screws for the fixation of unstable zygomatic fractures. J Oral Maxillofac Surg 1987; 45: 751-753.
11 Rozema FR, Bos RRM, Pennings AJ, Jansen HWB. Poly(L-lactide) implants in repair of defects of the orbital floor. An animal study. J Oral Maxillofac Surg 1990; 48: 1305-1309.

12 Bergsma JE, de Bruijn WC, Rozema FR, Bos RRM. Boering G. Late degradation tissue response to poly(Llactide) bone plates and screws. Biomaterials 1994; (in press).

13 Rozema FR, de Bruijn WC, Bos RRM, Boering G. Nijenhuis AJ, Pennings AJ. Late tissue response to bone plates and screws of poly(L-lactide) used for fracture fixation of the zygomatic bone. In: Doherty PI et al., eds. Biomaterial-Tissue Interfaces. Advances in Biomaterials, Vol. 10. Amsterdam: Elsevier, 1992: 349354.

14 Bergsma JE, Rozema FR, Bos RRM, de Bruijn WC. Foreign body reactions to resorbable poly(L-lactide) bone plates and screws used for the fixation of unstable zygomatic fractures. J Oral Maxillofac Surg 1993; 51: 666-670.

15 Fisher EW, Sterzel HJ, Wegmer G. Investigation of the structure of solution grown crystals of lactide copolymers by means of chemical reactions. Kolloid- $Z$ u $Z$ Polymere 1973; 252: 980-990.

16 Grijpma DW, Kroeze E, Nijenhuis AJ, Pennings AJ. Poly(L-lactide) crosslinked with spiro-bis-dimethylenecarbonate. Polymer 1993; 34(7): 1496-1503.

17 Böstman O, Päivärinta U, Manninen, M, Rokkanen P. Polymeric debris from absorbable polyglycolide screws and pins. Acta Orthop Scand 1992; 63(5): 555-559.

18 Böstman O, Päivärinta U, Partio E, Vasenius J, Manninen $M$, Rokkanen $P$. Degradation and tissue replacement of an absorbable polyglycolide screw in the fixation of rabbit femoral osteotomies. J Bone Joint Surg 1992; 74A(7): 1021-1031.

19 Rozema FR, Bos RRM, Boering G, et al. Tissue response to pre-degraded poly(L-lactide). In: Planck $H$, Dauner $M$, Renardy M, eds. Degradation Phenomena on Polymeric Biomaterials. Berlin: Springer, 1992: 123-131.

20 Reed AM, Gilding DK. Biodegradable polymers for use in surgery poly(glycolic)/poly(lactic-acid) homo- and copolymers: 2. In vitro degradation. Polymer 1981; 22: $494-498$.

21 Cha Y, Pitt CG. The biodegradability of polyester blends. Biomaterials 1990; 11: 108-111.

22 Leenslag JW, Pennings AJ. Synthesis and morphology of high molecular weight poly(L-lactide). Macromol Chem 1987; 45: 751-753.

23 Leenslag JW, Pennings AJ, Bos RRM, Rozema FR, Boering G. Resorbable materials of poly(L-lactide). VII. In-vivo and in-vitro degradation. Biomaterials 1987; 8: 311-314.

24 Zhang X, Wyss UP, Pichora D, Goosen MFA. An investigation of poly(lactic acid) degradation. I Bioactive Compat Polym 1994; 9: 80-100.

25 Vert M, Christel P, Chabot F, Leray J. Bioresorbable plastic materials for bone surgery. In: Hastings GW, Ducheyne P, eds. Macromolecular Biomaterials. Boca Raton, FL: CRC Press, 1984: 119-142.

26 Chawla AS, Chang TMS. In vivo degradation of poly(lactic acid) of different molecular weights. Biomater Med Dev Artif Organs 1985-86; 13: 153-162.

27 Nakamura T, Hitomi S, Watanabe S, et al. Bioabsorption of polylactides with different molecular properties. I Biomed Mater Res 1989; 23: 1115-1130.

28 Pistner H, Hoppert T, Gutwald R, Muling J, Reuther J. Biodegradation von polylactid-osteosynthesematerialien im langzeitversuch. Dtsch $Z$ Mund Kiefer Gesichts Chir 1994; 18: 50-53.

29 Pistner $\mathrm{H}$. $\mathrm{PhD}$ thesis, osteosynthese mit blinddubeln 
und platten aus biodegraddierbarem block poly(Llactid). Munich: Akademischer Verlag, 1993: 63.

30 Vert M, Li SM, Splenlehauer G, Guerin P. Bioresorbability and biocompatibility of aliphatic polyesters. J Mater Sci: Mater Med 1992; 3: 432-446.

31 Behling CA, Spector M. Quantitative characterization of cells at the interface of long-term implants of selected polymers. J Biomed Mater Res 1986; 20: 653-666.

32 Maguire JK. Coscia MF, Lynch MH. Foreign body reactions to polymeric debris following total hip arthroplasty. Clin Orthop 1985; 10: 213-221.

33 Sevastjanova NA, Mansurova LA, Dombrovska LE, Slutsski LI. Biochemical characterization of connective tissue reaction to synthetic polymer implants. Biomaterials 1987; 8: 242-246.

34 Böstman OM. Osteolytic changes accompanying degradation of absorbable tracture fixation implants. J Bone Joint Surg 1991; 73B: 679-682. 